\title{
ANALISA KEGAGALAN MENGGUNAKAN METODE FAILURE MODE AND EFFECT ANALISYS (FMEA) PADA UNIT OFF-HIGHWAY TRUCK 777D
}

\author{
Candra Dwi Putra ${ }^{1)}$, Akhmad Syarief ${ }^{2)}$, Hajar Isworo ${ }^{3)}$ \\ ${ }^{1), 2), 3)}$ Program Studi Teknik Mesin, Fakultas Teknik, Universitas Lambung Mangkurat \\ JL. Akhmad Yani Km.36 Banjarbaru, Kalimantan Selatan,70714 \\ Email : Jansayaman@yahoo.com
}

\begin{abstract}
Heavy equipment is a tool used to assist humans in performing construction and manufacturing projects to support good governance in the development of infrastructure as well as in the mining process. In use, heavy equipment is not a tool that has never experienced a failure in the system or group component, also in product design even on the work process during its life cycle which will lead to some disadvantages like low levels of production, not achieving the timetable or targets that have been set and also losses from repairing costs. Therefore, it is necessary to analyze the systems or any component group that experienced failure the most in the heavy equipment and also need to provide a "value" on the failure. With this, it's expected to help prevent a decrease in productivity by taking action a precaution against the systems that have high failure value. Value of the failure can be calculated based on unscheduled breakdown data that processed using Failure Mode and Effect Analysis (FMEA). This research was conducted using primary data obtained from the data breakdown and by collecting supporting data relating to the object of the report. With this research, it can be obtained the system or component group that has the largest failure value on the heavy equipment.
\end{abstract}

Keywords : FMEA, and Unscheduled Breakdown.

\section{PENDAHULUAN}

Off-Highway Truck (OHT) merupakan salah satu alat berat dimana berfungsi sebagai pemindah material dari satu tempat ke tempat lainnya. Di dalam industri khususnya industri pertambangan, penggunaan Off Highway Truck menjadi prioritas utama karena dapat memindahkan material dengan volume yang tinggi sehingga target produktivitas industri akan mudah tercapai.

Dalam penggunaannya alat berat bukanlah alat yang tidak pernah mengalami kegagalan pada sistem atau group component, juga pada desain produk bahkan pada proses kerja selama siklus hidupnya. Penggunaan alat berat yang kurang tepat dengan kondisi dan situasi lapangan pekerjaan akan mempengaruhi kerja dari unit yang juga akan menyebabkan beberapa kerugian, antara lain rendahnya tingkat produksi, tidak tercapainya jadwal atau target yang telah ditentukan dan juga kerugian biaya perbaikan unit yang tidak semestinya.

Untuk meningkatkan produktivitas unit, perlu dianalisa sistem-sistem atau group component mana saja yang mengalami kegagalan terbanyak yang dimiliki pada alat berat tersebut dan juga perlu memberikan "nilai” pada kegagalan yang terjadi. 
Dengan melakukan hal diatas, diharapkan mampu membantu mencegah penurunan produktivitas dengan melakukan tindakan - tindakan pencegahan terhadap sistem-sistem yang memiliki nilai kegagalan yang tinggi. Nilai dari kegagalan- kegagalan yang terjadi pada sistem yang menyebabkan penurunan produktivitas tersebut dapat dihitung berdasarkan data unscheduled breakdown yang diolah menggunakan metode Failure Mode and Effect Analysis (FMEA).

Tujuan dari penelitian ini adalah untuk menganalisa kegagalan sistem atau group component dengan Menggunakan Metode Failure Mode and Effect Analysis (FMEA) pada unit Off-highway Truck (OHT) $777 D$.

Mengingat luasnya ruang lingkup permasalahan yang ada maka permasalahan pada laporan tugas akhir ini dibatasi hanya pada :

1. Penelitian awal mengenai $R P N$ dengan metode FMEA untuk 1 unit Off-highway Truck (OHT) $777 D$.

2. Penjelasan hanya mencakup dari data unscheduled breakdown (kerusakan diluar jadwal) dan banyaknya kegagalan yang di alami 1 buah unit Off-highway Truck (OHT) 777D dalam kurun waktu 1 tahun (2014).

\section{TINJAUAN PUSTAKA}

FMEA merupakan teknik analitik secara kualitatif yang dapat memprediksi atau meramal kegagalan suatu unit atau produk dari kegagalan sistem atau group component. Analisa ini tidak memerlukan persamaan matematik dan statistik dan dapat diterapkan hanya kepada pengalaman dan pengetahuan yang konvensional. (Pascal, Irawan John. 2014).

RPN (Risk Priority Number) adalah indikator atau nilai kekritisan untuk menentukan tindakan koreksi yang sesuai dengan mode kegagalan. Nilai $R P N$ dapat dihitung dengan mangalikan rating dari severity (1-10), occurrence (1-10) dan detection (1-10).

$R P N$ digunakan oleh banyak prosedur FMEA untuk menaksir resiko menggunakan tiga kriteria berikut :

1. Keparahan efek (Severity) $S$

Severity merupakan suatu penilaian dari seberapa serius efek dari mode kegagalan terhadap pelanggan atau pengguna akhir.

2. Kejadian penyebab (Occurrence) O. Occurrence menunjukkan nilai keseringan suatu masalah yang terjadi karena potential cause.

3. Deteksi penyebab (Detection) $D$

Detection merupakan nilai alat kontrol yang digunakan untuk mendeteksi potential cause. 
Nilai $R P N$ merupakan hasil kali rating keparahan, kejadian, dan deteksi. Angka ini hanyalah menunjukkan rangking atau urutan defisiensi suatu sistem.

$$
R P N=\operatorname{Severity}(S) \times \text { Occurence }(O) \times \text { Detection }(D)
$$

Nilai RPN (Risk Priority Number) yang tinggi akan membantu dalam memberikan pertimbangan untuk tindakan korektif pada setiap mode kegagalan. (Sujarwadi, Mochamad. T. 2011).

Diagram tulang ikan atau fishbone diagram adalah salah satu metode atau tool didalam meningkatkan kualitas. Sering juga diagram ini disebut dengan diagram Sebab-Akibat atau cause effect diagram.

Pengertian breakdown didalam istilah dunia pertambangan adalah situasi dimana alat atau unit tidak dapat beroperasi sebagaimana mestinya akibat kerusakan sistem kerusakan alat atau unit tersebut atau sedang dilakukan proses perawatan atau perbaikan.

\section{METODOLOGI PENELITIAN}

Bahan yang menjadi objek penelitian ini adalah 1 Unit alat berat Off-highway Truck (OHT) 777D dan Data - data unscheduled breakdown pada tahun 2014 yang diperoleh dari PT. Saptaindra Sejati (SIS). Langkah-langkah penelitian dapat dilihat dalam diagram alir sebagai berikut: 


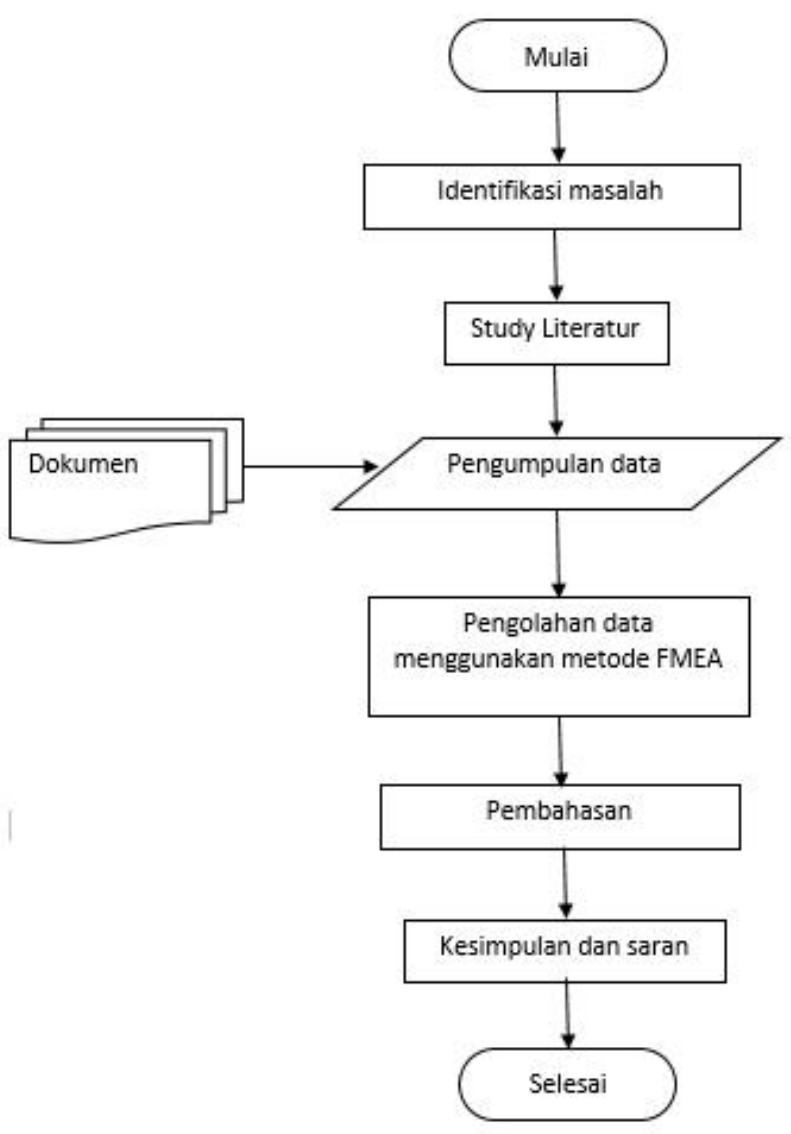

Gambar 1. Diagram Alir Penelitian

\section{HASIL DAN PEMBAHASAN}

Pengambilan data dilakukan dengan mengambil sampel unit Off-highway Truck (OHT) $777 D$ dengan mengambil 1 unit yang mengalami breakdown yaitu unit Off-highway Truck (OHT) $777 D$ dengan nomor lambung DT090-0066A dengan tujuan agar bisa mendapatkan kegagalan sistem atau group component yang memiliki nilai $R P N$ tertinggi pada tahun 2014 . Jumlah kegagalan pada sistem atau group component dapat dilihat pada table berikut:

Tabel 1. Data Jumlah Kegagalan

\begin{tabular}{|c|l|c|}
\hline No. & $\begin{array}{r}\text { Sistem dari Off-Highway Truck 777D Unit DT090-0066A (Group } \\
\text { Componen) }\end{array}$ & $\begin{array}{c}\text { Jumlah } \\
\text { kerusakan } \\
\text { Tahun } \\
2014\end{array}$ \\
\hline 1 & BRAKE SYSTEM & 1 \\
\hline 2 & ELECTRICAL & 5 \\
\hline 3 & ENGINE & 5 \\
\hline 4 & FRAME AND BODY & 3 \\
\hline 5 & OPERATOR STATION & 5 \\
\hline 6 & POWER TRAIN & 3 \\
\hline 7 & TYRE & 7 \\
\hline & \multicolumn{2}{r}{ Jumlah } \\
\hline
\end{tabular}


Setelah menganalisa dengan metode Failure Mode and Effect Analisys (FMEA) terhadap sistem-sistem Off-highway Truck (OHT) 777D dengan nomor lambung DT090-0066A yang berkaitan dengan data kegagalan pada sistem atau group component maka didapatlah nilai $R P N$ (Risk Priority Number) yang dapat dilihat pada table - tabel berikut berikut:

Tabel 2. RPN DT090-0066A

\begin{tabular}{|c|l|c|c|c|c|c|}
\hline NO & $\begin{array}{c}\text { Sistem dari Off-Highway Truck } \\
\text { 777D Unit DTO90-0066A (Group } \\
\text { Componen) }\end{array}$ & S E V & O C C & D E T & R P N & \%RPN \\
\hline 1 & BRAKE SYSTEM & 9 & 1 & 5 & 45 & $8 \%$ \\
\hline 2 & ELECTRICAL & 4 & 3 & 4 & 48 & $9 \%$ \\
\hline 3 & ENGINE & 8 & 4 & 6 & 192 & $36 \%$ \\
\hline 4 & FRAME AND BODY & 7 & 2 & 5 & 70 & $13 \%$ \\
\hline 5 & OPERATOR STATION & 2 & 2 & 7 & 28 & $5 \%$ \\
\hline 6 & POWER TRAIN & 8 & 2 & 4 & 64 & $12 \%$ \\
\hline 7 & TYRE TOTAL & 7 & 4 & 3 & 84 & $16 \%$ \\
\hline \multicolumn{7}{|c|}{ TIN } \\
\hline
\end{tabular}

Dari tabel diatas, maka didapatkan hasil dari 1 unit Off-highway Truck (OHT) 777D dengan nomor lambung DT090-0066A yang dianalisa menggunakan metode Failure Mode and Effect Analisys (FMEA) menunjukkan bahwa sistem atau group component yang memiliki kegagalan terbesar adalah Engine group dengan persentasi nilai $R P N 36 \%$.

Tabel 3. Kerusakan dari Engine Group DT090-0066A

\begin{tabular}{|l|l|c|}
\hline \multirow{4}{*}{ ENGINE GROUP } & HOSE AIR PRESSURE LEAK & 1 \\
\cline { 2 - 3 } & LOW POWER & 1 \\
\cline { 2 - 3 } & CAN'T START & 2 \\
\cline { 2 - 3 } & KEBOCORAN OLI ENGINE & 1 \\
\hline \multicolumn{2}{|c|}{ JUmlah } & 5 \\
\hline
\end{tabular}

Berdasarkan tabel 3, dapat dilihat beberapa kerusakan yang terjadi pada Engine group, dari beberapa kerusakan tersebut masalah Engine Can't Start lah yang paling sering mengalami kerusakan. Berikut adalah diagram fishbone sebagai metode yang digunakan untuk menganalisa penyebab seringnya terjadi masalah Engine can't start pada unit DT090-0066A. 


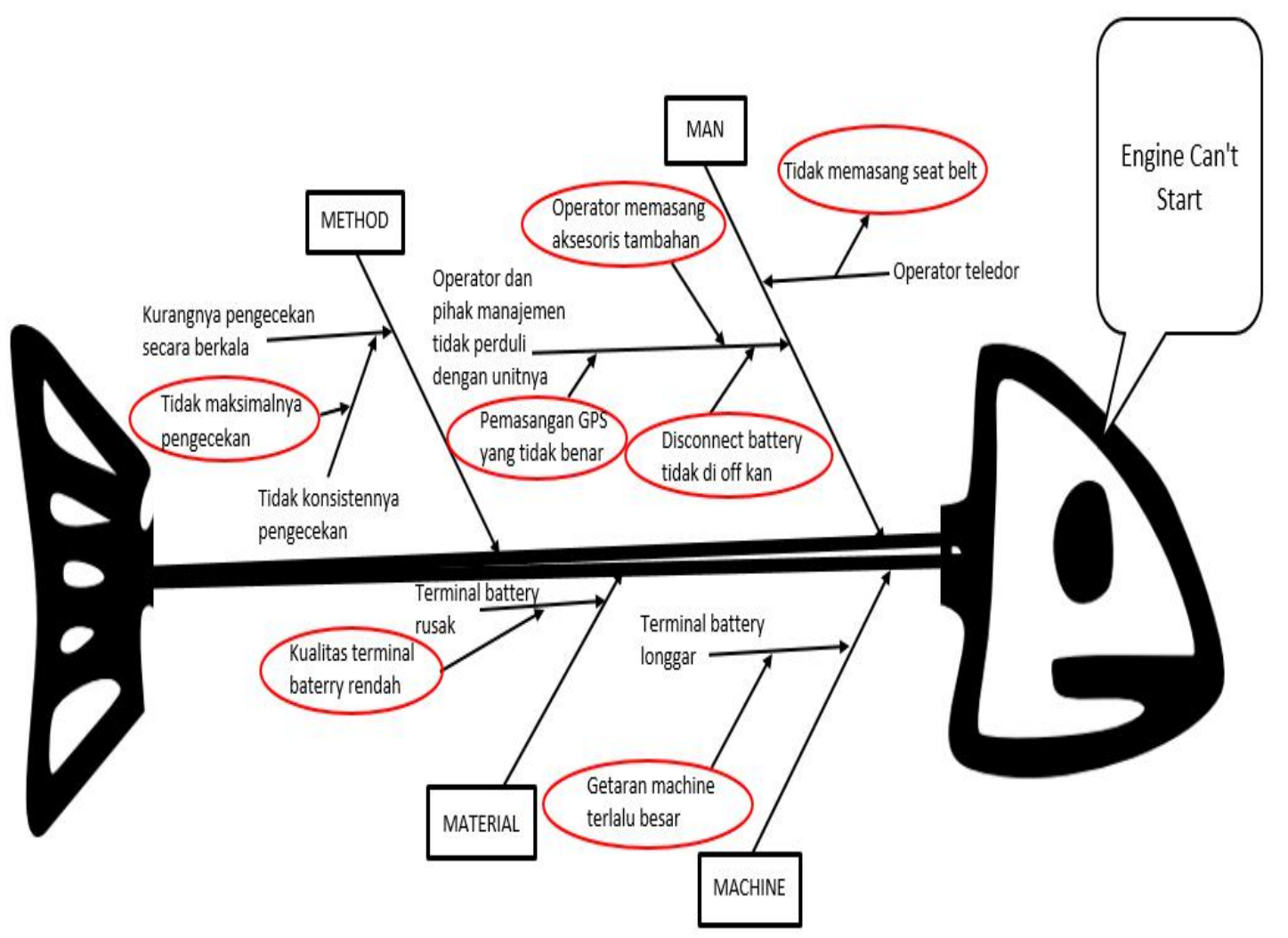

Gambar 2. Diagram Fish Bone

Berdasarkan analisa dengan menggunakan metode fishbone diagram sebelumnya, diketahui ada beberapa faktor penyebab yaitu faktor Man, Machine, Methode, Material yang bisa membuat seringnya terjadi kegagalan pada Engine group pada unit DT090-0066A, yaitu masalah Engine can't start. Dari beberapa faktor tersebut akan dijelaskan apa saja akar permasalahan yang memebuat kegagalan itu terjadi, yaitu :

- Man (Manusia)

$>$ Operator teledor

Operator sering lupa memasang seat belt, yang mana seat belt tersebut sudah dimodifikasi, sehingga membuat engine tidak bisa dihidupkan apabila seat belt tersebut tidak terpasang. Modifikasi tersebut bertujuan untuk meningkatkan safety kepada pengguna unit tersebut.

$>$ Operator dan pihak manajemen tidak perduli dengan unitnya

- Operator memasang aksesoris tambahan 
Operator sering kali menambahkan perangkat speaker aktif di dalam cabin, hal ini sering menyebabkan battery drop, sehingga setelah pengguaan unit, engine akan mengalami masalah can't start pada saat unit akan digunakan kembali.

- Disconnect battery tidak di off kan

Pengguna terakhir unit sering kali lupa untuk disconnect baterry pada saat unit tersebut parkir dalam jangka waktu yang cukup lama, hal ini menyebabkan arus battery terbuang dengan percuma.

- MACHINE (Mesin)

$>$ Terminal battery longgar

- Getaran machine terlalu besar

Geteran machine yang terlalu besar sering menyebabkan longgarnya terminal battery, sehingga arus battery yang dibutuhkan untuk melakukan start engine tidak mencukupi, dan terjadilah engine can't start.

- METHOD (Metode)

Kurangnya pengecekan battery secara berkala

Tidak konsistennya pengecekan

- Tidak maksimalnya pengecekan

Pengecekan battery hanya dilakukaan pada saat servis berkala, sehingga kerusakan pada komponen battery tidak bisa di cegah secara dini. Kerusakankerusakan tersebutlah yang sering menyebabkan engine can 't start

- MATERIAL (Bahan Baku)

Terminal battery rusak

- Kualitas terminal baterry rendah 
Terminal battery sering mengalami kerusakan, sehingga arus battery yang dibutuhkan untuk melakukan start engine tidak mencukupi, dan terjadilah engine can't start.

Dari penjelasan akar permasalahan yang memebuat seringnya kegagalan itu terjadi, berikut adalah solusi yang dapat mengurangi kemungkinan terjadinya kegagalan tersebut :

a. MAN (Manusia)

Seperti yang kita tau, peran dan pengetahuan manusia dalam penggunaan unit alat berat sebagai alat produksi sangat penting. Dari beberapa kejadian, faktor kesalahan dari manusia begitu sering terjadi, memberikan pelatihan-pelatihan baik dari sisi skill maupun kedisiplinan menjadi solusi dasar agar kesalahan itu tidak terjadi kembali.

b. MACHINE (Mesin)

Getaran yang terjadi pada unit alat berat pada saat unit beroprasi sering mengakibatkan longgarnya beberapa komponen termasuk terminal battery, longgarnya terminal battery akibat getaran tersebut dapat diminimalisir dengan cara manambahkan bantalan karet pada bagian braket pengunci battery.

c. $M E T H O D$ (Metode)

Jangka waktu pengecekan battery yang terlalu jauh mengakibatkan kerusakan pada komponen baterry tidak bisa di cegah sejak dini, hal ini lah yang menyebabkan banyak kerusakan yang tidak di inginnyan, akan lebih baik jika planner menambahkan jadwal pengecekan battery agar masalah yang sering terjadi tidak terulang kembali.

d. MATERIAL (Bahan Baku)

Terminal battery seringkali rusak, selain karna faktor usia, kerusakan juga bisa terjadi karena getaran unit yang mengakibatkan patahnya terminal battery. Hendaknya engineer menggantinya dengan terminal battery dengan material yang lebih bagus. 


\section{KESIMPULAN}

Adapun kesimpulan yang dapat diambil dalam penyusunan tugas akhir ini adalah :

1. Dari tabel data perhitungan $R P N$ (Risk Priority Number) pada 1 buah unit Off-highway Truck $777 D$ pada bab IV, maka dapat disimpulkan bahwa dari 1 buah unit Off-highway Truck 777D dengan nomor lambung DT090-0066A yang dianalisa menggunakan metode Failure Mode and Effect Analisys (FMEA) menunjukkan bahwa sistem atau group component yang memiliki kegagalan terbesar adalah Engine group dengan persentase nilai $R P N 36 \%$.

2. Beberapa penyebab terjadinya kegagalan yang dianalisa menggunakan diagram fishbone tersebut seperti : Man, Machine, Methode, Material.

\section{DAFTAR PUSTAKA}

[1] Copyright 2014 Majalah Shift Indonesia. Dari (http://shiftindonesia.com/10-langkahlakukan-FMEA/) Dikutip tanggal 28 Juli 2015

[2] Febriyanto, Arif. 13 Februari 2010. Bathup Curve (Kurva Bak Mandi). Dari www.ariffebriyanto.com/2010/02/bathup-curve-kurva-bak-mandi.html. Dikutip tanggal 29 Juli 2015

[3] Rengkodriders. 9 November 2011. Macam - macam Alat Berat dan Fungsinya. Dari rengkodriders.wordpress.com/2011/11/09/macam-macam-alat-berat-dan-fungsinya/ Dikutip tanggal 27 Juli 2015

[4] Sujarwadi, Mochamad. T. 20 Desember 2011. Failure Mode and Effect Analysis (FMEA) Method. Dari http://mtsujarwadi.blogspot.com/2011/12/failure-mode-and-effectanalysis-fmea.html. Dikutip tanggal 27 Juli 2015

[5] Sugianto, Soleh.13 Oktober 2008. Potential Failure Mode and Effect Analysis. Dari http://solehsugianto.blogspot.sg/2008/10/potential-failure-mode-and-effects.html, Dikutip tanggal 28 Juli 2015

[6] Pramono, Wishnu Arief. Desember 2012. Failure Mode and Effect Analysis. Dari http://www.wishnuap.com/2012/12/failure-mode-and-effect-analysis-fmea.html, Dikutip tanggal 28 Juli 2015

[7] (journal.umsida.ac.id/files/Mesin_RF.pdf) (google search) Dikutip tanggal 28 Juli 2015 
[8] (http://ejournal.undip.ac.id/index.php/jgti/article/viewFile/1926/1687) Dikutip tanggal 29 Juli 2015

[9] Rangkuti, Widia Boru. 5 April 2011. Diagram Pareto. Dari rwiewied.blogspot.sg/2011/04/digram-pareto.html. Dikutip tanggal 29 Juli 2015

[10] Wijayanto, Tizhart. 2012. Istilah Umum Di Pertambangan. Dari tizarwijayanto.blogspot.sg/pmotto-1-lupakan-jasa-diri-sendiri.html. Dikutip tanggal 29 Juli 2015. 